\title{
Rethinking the Factor of Duration for Professional Development: A Workshop- Seminar-Demonstration Class Model for Science Teachers
}

\author{
Nuo Li ${ }^{1}$, Enshan Liu ${ }^{1 *}$, Cheng Liu ${ }^{1}$, Shuchen Guo ${ }^{1,2}$ \\ ${ }^{1}$ College of Life Sciences, Beijing Normal University, Beijing, CHINA \\ ${ }^{2}$ School of Teacher Education, Nanjing Normal University, Nanjing, CHINA
}

Received 31 August 2021 - Accepted 5 November 2021

\begin{abstract}
Participating in effective professional development (PD) activities is crucial for helping teachers improve the quality of pedagogy and students' learning results. Numerous factors influence the design of effective PD, one of which is duration. However, many teachers do not find much time to participate in long-term concentrated and continuous PD due to their heavy workloads. Based on this consideration, this paper presents the Workshop-Seminar-Demonstration Class PD (WSDPD) model, which addresses the factor of duration by shortening the hours of contact, lengthening the total span of time required, and integrating elements such as active learning and expert follow-up to improve teachers' practical teaching methods. With "Teaching for Conceptual Change" as the theme and junior high school science teachers as participants, the results of the study show that WSD-PD can serve teachers by generating willingness to improve teaching practices for and influence teaching behaviors in them. The settings of different activities in this model are also considered to play distinct and indispensable roles in the program.
\end{abstract}

Keywords: duration, professional development, science teachers, teaching practices

\section{INTRODUCTION}

Teacher quality has important implications for student learning (Kane et al., 2013). Effectively designed professional development (PD) programs can enhance teachers' professional knowledge, skills, and attitudes, thereby improving students' learning effectiveness and achievements (Blank \& de las Alas, 2009; Guskey, 2003). Currently, many PD programs in science education are focused on the context of curricular reform; they are designed in relation to reform efforts and aimed at successful educational innovation (Dall'Alba \& Sandberg, 2006; Luft \& Hewson 2014; van Driel et al., 2012). Education researchers are responsible for providing teachers with more comprehensive support, to help them acquire essential knowledge. Additionally, they should facilitate the development of teaching practices that are aligned with science education reform (Pringle et al., 2020). More effort should be made to provide updated and effective PD activities for science teachers to ensure the output of training results (Aldahmash et al., 2019).
Currently, a variety of PD training models are available worldwide. Whether in traditional or modified types of activities, a number of key factors, such as duration, active learning, coherence, and expert followup affect the effectiveness of PD (Desimone, 2009; Garet, 2001; Guskey \& Yoon, 2009; Wilson, 2013). Although PD does not always include most of these characteristics (Cordingly et al., 2015), short duration, lack of meaningful follow-up, and limited opportunities for practice and feedback limit the effectiveness of PD, especially for science teachers (Darling-Hammond et al., 2009). This study aims to establish a PD model that integrates different types of training activities and key factors that determine effective PD, helping teachers better grasp training content and improve their teaching practices despite extremely busy daily work schedules. Specifically, this study examined how to understand and apply the "duration" factor more effectively. 


\section{Contribution to the literature}

- PD plays an important role in teachers' growth. However, limited by the heavy workloads, many teachers find it difficult to find time to participate in continuous and long-term PD processes. The WSD-PD model constructed in this study can help teachers use limited time to participate in effective PD activities.

- The training theme of this study was "Teaching for Conceptual Change." At present, abundant studies focus on the changes in students, yet few focus attention on the changes in teachers' behavior, and the application rate of this topic in classroom practice in developing countries is very low. Therefore, this study focuses on the behavioral changes of teachers in training for conceptual change.

- The implementation of WSD-PD can provide effective parameters for the discussion of program fidelity, especially with the aim of finding a moderate fidelity threshold sufficient to yield positive program outcomes.

\section{THEORETICAL FRAMEWORK}

\section{Effective PD Framework}

Professional Development has long been recognized as a tool for supporting teacher learning and growth (Granger, 2019). A well-designed PD program can be an effective strategy to facilitate reform efforts in enhancing teachers' knowledge and teaching practices, and can ultimately benefit students (Avalos, 2011; Day, 1999; Fullan, 2008). Therefore, researchers should support teachers in implementing what they learn during PD when they return back to the classroom (Fogleman et al., 2011).

Researchers have proposed several PD models that could maximize positive outcomes. Wilson (2013) pointed out that researchers have a certain degree of consensus regarding the form of high-quality PD. She proposed a consensus model for effective PD. Desimone (2009) identified the characteristics of high-quality PD with (1) content focus, (2) active learning, (3) coherence, (4) duration, and (5) collective participation, and proposed a conceptual framework. This model has been widely accepted, and adopted in science education (Yang et al., 2020). However, many researchers acknowledge that the PD process is more complex and iterative than a simple chain of activities (Carpendale et al., 2021; Desimone, 2009; McChesney \& Aldridge, 2019). Clarke and Hollingsworth's (2002) interconnected model involves the external domain, personal domain, domain of practice, and domain of consequence to avoid linear chains. McChesney and Aldridge (2019) proposed a new conceptual model which involving five stages: intended $\mathrm{PD}$, received $\mathrm{PD}$, accepted $\mathrm{PD}$, applied $\mathrm{PD}$, and student impact, and various barriers influenced whether teachers participating in PD were able to progress to each successive stage. Researchers argue that different models are appropriate for different purposes contexts (Boylan et al., 2018; Carpendale et al., 2021). Moreover, implementation fidelity is also considered critical to modern PD evaluation (Hill \& Erickson, 2019).

\section{The Status of Duration}

Most of the literature exploring effective PD factors has long regarded duration as an important factor (Borko et al., 2010; Desimone, 2009; Grossman, 1995; Guskey, 1999; Kennedy, 1998; Wilson, 2013). As part of the dosage fidelity in the domain of implementation fidelity (Hill \& Erickson, 2019), researchers could organize PD effectively over a substantial period of time, focusing especially on knowledge and pedagogy (Guskey, 1999). A sufficient duration can provide teachers opportunities to consistently generate new knowledge and understanding. Moreover, it can also ensure teachers have enough time to apply new knowledge in classroom teaching and obtain practical feedback (Garet, 2001; Grossman, 1995).

However, some researchers believe that excessive training time has no practical effect (Telese, 2008). In this study, we believe that the definition of "duration" should be based on the required effective time for efficient organization. It should not only consider the teachers' ability to understand and retain the material taught during training, but also provide practice at a sufficient interval and time to gathering feedback. Specifically, the total span of time and the contact hours should be classified differently (Kennedy, 2016). Lengthening the total span of time to leave a sufficient interval for teachers to practice might help them better master the training content and transform it into classroom practices. This approach is key in our PD design.

\section{Other Factors Affecting the Effectiveness of PD}

Additional factors have also been proven to affect the effectiveness of PD, such as positive learning opportunities (Borko et al., 2010; Grossman, 1995; Loucks-Horsley et al., 1998; van Driel et al., 2012) and expert follow-up to provide guidance at any point in time (Bransford et al., 2005; Guskey \& Yoon, 2009). Kowalski et al. (2020) classified these features into two categories: core features and structural/process features. Core features include a focus on content and coherence with teacher beliefs and state or district policies, while 


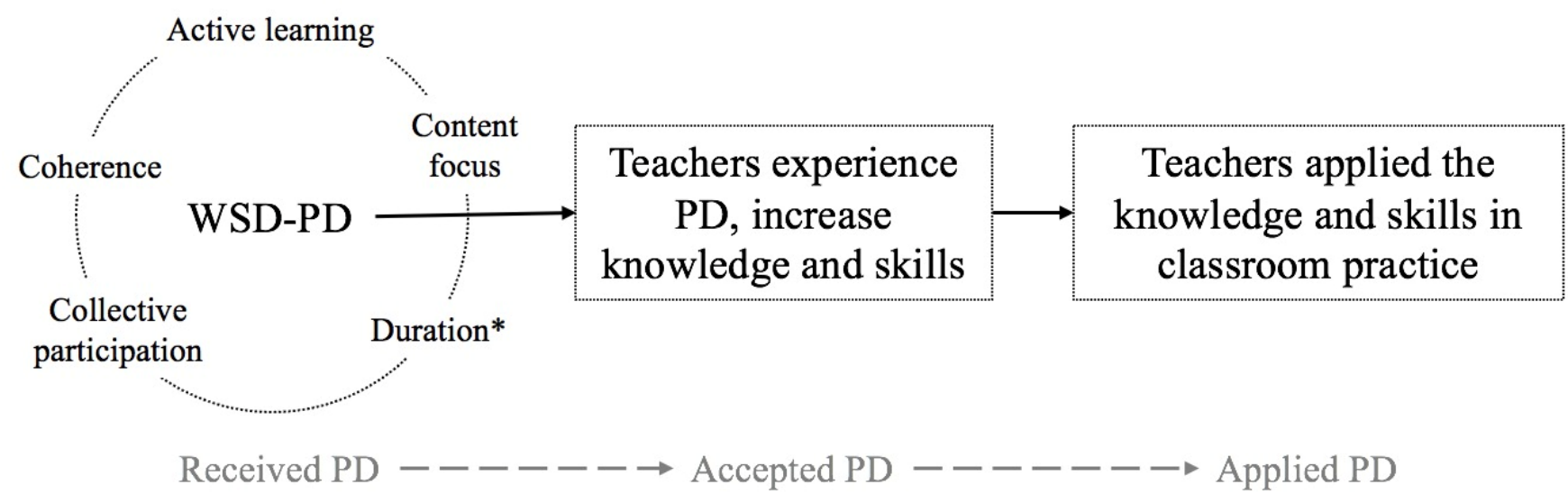

Note. *Duration here is a long span of time and short contact hours

Figure 1. The design of the PD framework in this study

structural/process features include duration, teacher collaboration with the opportunity to reflect on practice, and collective participation.

In recent years, some researchers have proposed additional factors that may affect the implementation of PD and render even certain well-designed literaturebased PD models incapable of facilitating the attainment of desired teaching and learning gains. McChesney and Aldridge (2019) suggested that various barriers include school related factors, language issues, teachers' cognitive access and the perceived fit that may exist in the process of PD implementation. Hill and Erickson (2019) believe that the estimates of implementation fidelity also can help explain null results, and divide these results into structural fidelity, process fidelity and dosage fidelity. Carpendale et al. (2021) mentioned that researchers should pay attention to how highly accomplished teachers respond to PD situations and balance fidelity with expectations of teacher agency. In addition, professional identity, students' homework, the role of principals and school leaders, curriculum materials, and teacher reflection are also considered by some researchers to be factors that affect the implementation of PD (Desimone, 2009; Keisler, 2017).

\section{Framework of the PD Model in this Study}

Based on the conceptual framework of effective teacher PD (Desimone, 2009; Wilson, 2013), we designed the WSD-PD model (Figure 1). The PD program in this study contains five parts: (1) training focusing on teaching for conceptual change (content focus), (2) trying out new teaching strategies in designing new classroom practices and observation classes (active learning) (Borko et al., 2010; Van Driel et al., 2012), (3) meeting the needs of teachers, schools, and districts (coherence), (4) one year as the span of time (duration, key factor), and (5) professional learning communities in the form of more comprehensive and strategically combined activities (collective participation) (Kennedy, 1998; Loucks Horsley et al., 1998).
Based on the above, our framework refers to McChesney and Aldridge's (2019) conceptual model. To fully consider the structural barriers (school-related factors and language issues), we focused on the process from received PD to accepted PD, and then applied PD in the design process, and considered the fidelity level as much as possible in the implementation process. Our study addresses the following research questions: (1) Can WSD-PD help teachers generate a willingness to improve their teaching, especially in lesson plan design? (2) Can teachers apply what they have learned from training to classroom teaching practices? (3) What are the teachers' evaluations of different activities in the WSDPD?

\section{METHODOLOGY}

\section{The Design of and Information about the WSD-PD Model}

Professional Development is of great significance to teaching. However, most teachers do not have much time available to actively participate in PD. This poses a major challenge to the efficient use of distributable time to improve the effectiveness of a PD program. Considering this problem, our study attempts to establish a Workshop-Seminar-Demonstration class Professional Development (WSD-PD) model (Figure 2).

The WSD-PD model uses teachers' distributable time to minimize the impact on their daily work. It reduces the contact hours (approximately 70) while lengthening the total span of time (a whole year). To make effective use of the extended interval, this model is structured in three cycles, each comprising three different activities. It is based on the progression from theoretical learning (workshop) to problem solving (seminar) to practical applications (demonstration class). First, teachers conduct a theoretical study during a workshop to acquire knowledge and teaching strategies, guided by professional researchers in the field of teaching of conceptual change. After independently exploring the 


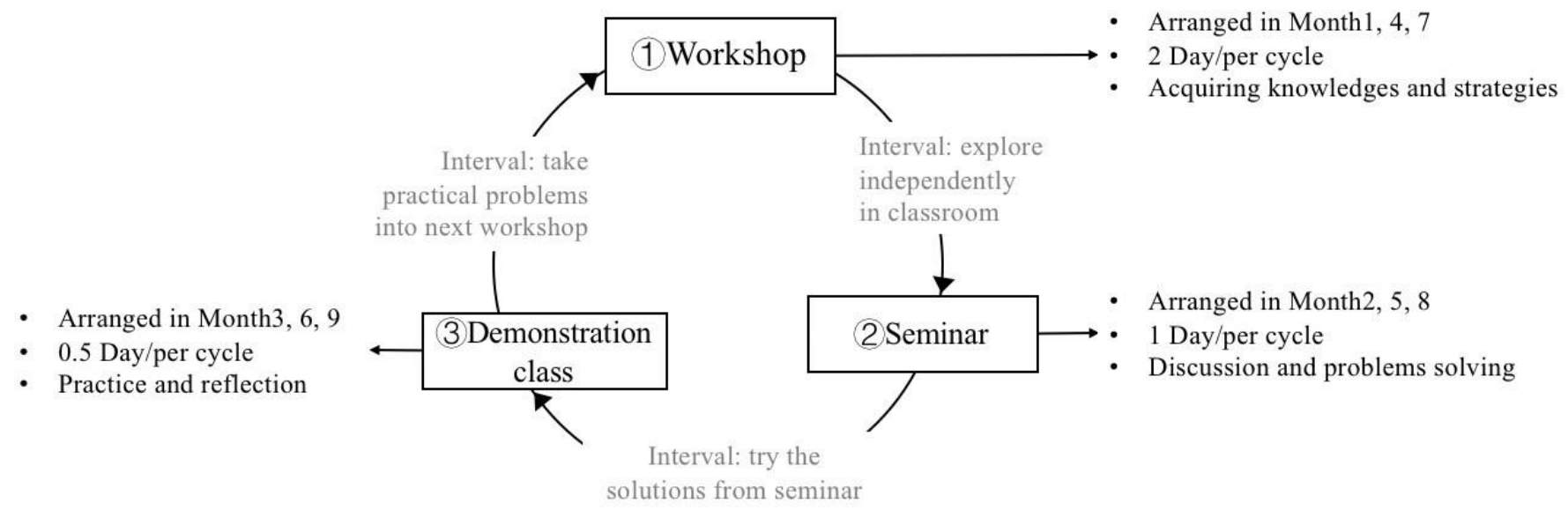

Note. a. Black parts show the activities in PD, grey parts show what teachers do during the interval. b. Winter and summer vacation have been removed, and the remaining 9 months of the year are defined as months 1-9

Figure 2. The structure of WSD-PD model

Table 1. Basic information of the participants

\begin{tabular}{lcccc}
\hline Participant & Gender & $\begin{array}{c}\text { Teaching } \\
\text { experience }\end{array}$ & Subject & $\begin{array}{c}\text { Academic } \\
\text { degree }\end{array}$ \\
\hline A & Female & 4 & biology & master \\
B & Female & 17 & physics & bachelor \\
C & Female & 9 & chemistry & bachelor \\
D & Female & 5 & chemistry & master \\
E & Female & 7 & biology & master \\
F & Female & 20 & biology & master \\
G & Female & 5 & biology & doctor \\
H & Female & 4 & physics & master \\
I & Male & 12 & physics & bachelor \\
J & Female & 16 & chemistry & bachelor \\
K & Female & 3 & biology & master \\
L & Female & 7 & biology & master \\
M & Female & 17 & physics & bachelor \\
\hline
\end{tabular}

theory during the interval, they participate in a seminar to communicate with fellow teachers and experts engaged in science teaching in universities to exchange experiences, feelings and difficulties in implementation and obtain preliminary solutions and new-found inspiration. After trying out new ideas from the seminar, teachers complete the task of reflection during the demonstration class, with one teacher volunteering to teach while the rest observe. Following this, all of the teachers engage in discussion to analyze and obtain feedback from the demonstration class to promote their reflections toward actual teaching. All new problems encountered in actual teaching are taken up in the subsequent round of the workshop for continued learning.

\section{Participants}

The participants in this study were junior high school (grade 7-9) science teachers from 16 different school districts in Beijing, China. This included 10 physics teachers, 10 chemistry teachers and 10 biology teachers (total $\mathrm{N}=30$ ). The levels of teaching experience ranged from 3-24 years, with academic degrees ranging from

\begin{tabular}{lcccc}
\hline Participant & Gender & $\begin{array}{c}\text { Teaching } \\
\text { experience }\end{array}$ & Subject & $\begin{array}{c}\text { Academic } \\
\text { degree }\end{array}$ \\
\hline $\mathrm{N}$ & Female & 17 & biology & bachelor \\
$\mathrm{O}$ & Female & 18 & physics & bachelor \\
$\mathrm{P}$ & Female & 16 & biology & bachelor \\
$\mathrm{Q}$ & Female & 24 & chemistry & bachelor \\
$\mathrm{R}$ & Female & 18 & chemistry & bachelor \\
$\mathrm{S}$ & Female & 14 & chemistry & bachelor \\
$\mathrm{T}$ & Male & 17 & biology & bachelor \\
$\mathrm{U}$ & Female & 5 & physics & bachelor \\
$\mathrm{V}$ & Male & 3 & chemistry & master \\
$\mathrm{W}$ & Female & 18 & biology & bachelor \\
$\mathrm{X}$ & Female & 4 & chemistry & master \\
$\mathrm{Y}$ & Female & 13 & physics & bachelor \\
$\mathrm{Z}$ & Female & 15 & physics & bachelor \\
\hline \multicolumn{5}{c}{}
\end{tabular}

undergraduate to doctoral levels. Of the teachers, 6 were male and 24 were female. All the teachers signed up for the PD voluntarily and none of them were paid for their participation. Since the program was approved by the Municipal Education Department in the early stage of implementation, all participants received support from their respective schools and school districts' leaders. Among the participants, four discontinued the training for personal reasons and did not submit complete matching data. Thus, the survey sample comprised 26 participants for the final analysis. Table 1 presents basic information pertaining to the 26 teachers.

\section{Training Content and Background}

Due to the adoption of a new PD model, the selection of a training theme with a strong theoretical basis and mature teaching strategies was preliminary work in this study. Considering this aspect, we eventually chose "Teaching for Conceptual Change" as the training content. As an effective framework for improving science teaching (Treagust, 2003), research on this topic has received increased attention from researchers worldwide ( $\operatorname{Lin} 2016)$. However, there is a large number 
of teachers who fail to understand its meaning accurately; they lack the knowledge to design teaching activities that support conceptual change in students (Gomez-Zwiep, 2008). Through the analysis of previous studies, it was found that there are few empirical studies focusing on PD to facilitate teachers acquiring practical teaching strategies on this topic in China (Li et al., 2018). Our study also tested the participants using questionnaires before training. Only $19.2 \%$ of teachers were able to adequately articulate the key words of the conceptual change theory, and very few of them knew the teaching strategies. More than $80 \%$ of the teachers had never heard of its definition. We therefore took teaching for conceptual change as the training theme while focusing on exploring the effectiveness of the WSD-PD model. We analyzed whether WSD-PD can effectively help teachers understand a new teaching strategy and further apply it to instructional practice.

\section{Data Sources and Analysis}

In this study, a mixed methods approach was employed to understand how teachers' knowledge and practices were impacted. By combining quantitative and qualitative approaches, researchers can better understand the research questions and achieve the research objectives (Johnson \& Christensen, 2004; Yin, 2006). Therefore, the data collected in this study was derived from multiple sources, including questionnaires, lesson plans, classroom videotapes, and teachers' discussions during the training.

Regarding the data analysis, the quantitative data mainly emanated from three sources: a questionnaire, lesson plan coding, and classroom videotape coding. The questionnaire survey was conducted after training to obtain teachers' feedback on the WSD-PD. The questionnaire employed a five-point Likert-type scale, ranging from "completely disagree" (1) to "completely agree (5)." The average value of each survey item was calculated to understand the teachers' evaluation of each type of activity and its existence value in the WSD-PD. Each teacher submitted a lesson plan and a classroom videotape before and after the WSD-PD. Combined with existing research on classroom performance of teaching for conceptual change, our study designs coding Framework 1 (FW1) for lesson plans and Framework 2 (FW2) for classroom videotapes (Bybee et al., 2006; Lerman, 1989; Osborne \& Wittrock, 1985; Posner et al., 1982; Santrock, 2006; Smith et al., 1993; Wittrock, 1974; Vosniadou, 2003). These frameworks were reviewed and discussed by two professors and analyzed after three revisions. Coding worksheets were provided for different coders. Both FW1 and FW2 were divided into different stages according to the 5E teaching model, and binary coding was used for all codes. Any content that complied with the coding was assigned a value of 1 ; otherwise, it was assigned 0. Moreover, FW1 and FW2 each contained 18 codes (Table 2), and the total score of the sample was the sum of the 18 coding values. Simultaneously, we also used the framework of the Trends in International Mathematics and Science Study (TIMSS) video studies (Stigler et al., 1999), and chose the content and teacher behavior-related codes in this framework to analyze the videotapes for a second time, to understand whether teachers had changed their classroom behaviors. In addition, this study conducted a qualitative analysis of teachers' lesson plans and classroom videotapes. Combined with data from teachers' discussions and seminar speeches in the

Table 2. Coding items in FW1 and FW2

Stage Coding

1 Engagement 1.1 Design activities to identify and explore students' preconceptions (FW1 \& FW2)

1.2 Use activities designed to stimulate students' interest in learning new conceptions (FW1 \& FW2)

1.3 Induce cognitive conflict in students (FW1 \& FW2)

1.4 Create context or situations to introduce new conceptions (FW1 \& FW2)

2 Exploration 2.1 Use a variety of teaching resources to help students complete the paradigm shift (FW1 \& FW2)

2.2 Encourage students to cooperate, interact or discuss; teachers do not give instructions or explanation directly (FW1 \& FW2)

2.3 Create inquiry opportunities for students (FW1)

2.3 Provide students with time to think about questions (FW2)

2.4 Use conceptual change models of teaching 2.4 Do not directly reject students' wrong (FW1) answers/conceptions (FW2)

3 Explanation 3.1 Connect with students' preconceptions as a basis of new conception learning (FW1 \& FW2) 3.2 Encourage students to summarize and generate conceptions and understanding independently (FW1 \& FW2)

3.3 Provide students with opportunities to express their conjectures and understandings and provide evidence to clarify their explanations (FW1 \& FW2)

3.4 Classroom design ultimately delivers clear 3.4 Pay attention to the growth of students' and important concepts to students (FW1) understanding (FW2)

Note. a. The stages in which the coding were divided only indicated a general situation, and the actual stage in which each item appeared in the classroom could vary. b. In FW1 and FW2, thirteen codes were the same, and five codes were different between FW1 and FW2 owing to different data formats. Take 2.3 as example, video coding observed whether teachers gave students time to think after questioning, but this type of data cannot be reflected in the lesson plan. 
Table 2 (continued). Coding items in FW1 and FW2

\begin{tabular}{|c|c|}
\hline Stage & Coding \\
\hline 4 Elaboration & 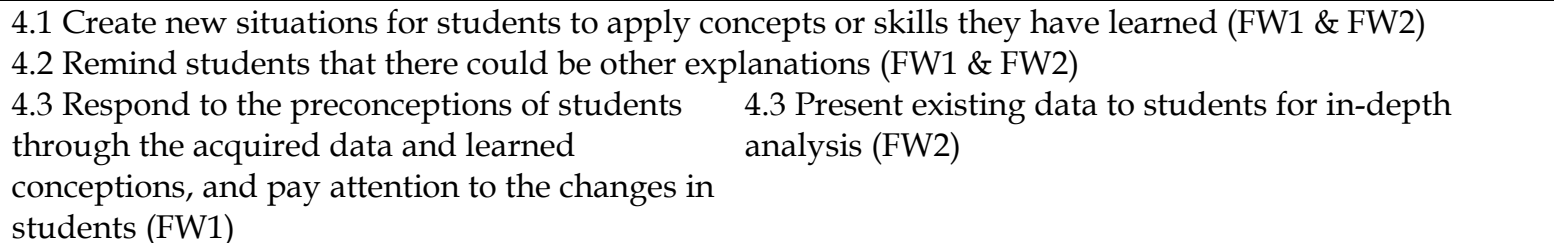 \\
\hline 5 Evaluation & $\begin{array}{l}\text { 5.1 Test students' understanding and applications of new conceptions and skills (FW1 \& FW2) } \\
\text { 5.2 Be able to use multiple evaluation methods, } 5.2 \text { Ask reflective and open questions (FW2) } \\
\text { such as diagnostic, formative or final evaluations } \\
\text { (FW1) } \\
\text { 5.3 Develop and use evaluation methods that may assist teachers to track and locate students' conceptual } \\
\text { changes (FW1 \& FW2) }\end{array}$ \\
\hline
\end{tabular}

process of training, we aspired to describe the possible changes in teachers in a more in-depth manner in the WSD-PD program.

\section{RESULTS}

\section{Willingness to Change and Changes in Lesson Plans}

The questionnaire survey results revealed that most teachers had a higher level of willingness to practice after the WSD-PD. Twenty-four (92.3\%) and 21 (80.7\%) teachers reported that they would apply, or had already applied, the training content into practices, respectively. All $26(100 \%)$ teachers were willing to share the content they learned with other teachers. Among them, 25 $(96.2 \%)$ teachers had already conducted and shared such learning during training. To understand whether their willingness with respect to teaching practices could be authentically implemented as described, we performed a coding analysis of their pre-training and post-training lesson plans. Two trained doctoral researchers independently encoded $20 \%$ of the total data using FW1. The kappa value assignment was $0.898(>0.75)$ for the Sig. $=0.00(<0.05)$ and McNemar test Sig. $=1.000(>0.75)$, indicating that the two raters had effective consistency. After discussion, researchers reached a consensus on the coding results. The first author of this paper completed the remainder of the coding, wherein 936 lesson plan codes generated by 26 paired samples were analyzed. Except for one teacher who scored lower in the postanalysis than the pre-analysis $(9 \rightarrow 7)$ and one teacher who scored the same $(11 \rightarrow 11)$, all the other post-analysis data scores were higher than those at the pre-analysis stage, with a minimum difference of 1 and maximum of 8. Considering that the samples were few, related, and with unknown distributions, the Wilcoxon method was selected to test the differences. Since Asymp.Sig $=0.00<0.05$, it was considered that there is a significant difference between the pre- and post-data.
This finding shows that there was an obvious difference between the teachers' lesson plans before and after the WSD-PD. Specifically, the training had a positive impact on the teachers and could help them apply conceptual change strategies in teaching at the lesson plan design stage. To further understand the changes in each teacher independently, a statistical analysis was conducted on each paired sample. Since the codes were binary variables, the Wilcoxon and McNemar methods were used to test the differences between lesson plans. As per the Asymp.Sig. value shown in Table 3, 13 teachers showed significant differences in the Wilcoxon test, of which 10 also showed significant differences in the McNemar analysis.

Since the data were expressed in words, the lesson plan designs were very visual. Taking code 1.1 as an example, data that was assigned a value of 1 indicated that teachers could identify students' existing preconceptions or current misconceptions through questionnaires, literature reviews, or activities designed before class. The remaining classroom engagement stages, which do not involve teachers' attention to students' preconceptions, were assigned a value of 0 . The following two teachers' teaching plans illustrate an example with a value of 1 . In the results section, all the data, in Chinese, were translated into English by one researcher, and translated back into Chinese by another researcher to ensure the accuracy of the data expressions:

J-Post: [Engagement] Using the pre-class questionnaire, [I] found you already had some knowledge about solutions. The following projection shows your answers. Is a solution really what you think [it] is? You will know at the end of the current lesson.

P-Post: Students' preconceptions: 1. Skeletal muscle belongs to muscle tissue; 2. Skeletal muscle has no function in the process of 
Table 3. Analysis results of the difference between individual teacher's pre- and post-analysis

\begin{tabular}{lcccc}
\hline \multirow{2}{*}{ Sample } & \multicolumn{2}{c}{ Lesson Plans } & \multicolumn{2}{c}{ Videotapes } \\
\cline { 2 - 5 } & Wilcoxon & McNemar & Wilcoxon & McNemar \\
\hline $\mathrm{A}$ & $.014^{*}$ & $.031^{*}$ & $.003^{*}$ & $.004^{*}$ \\
$\mathrm{~B}$ & $.008^{*}$ & $.016^{*}$ & $.002^{*}$ & $.002^{*}$ \\
$\mathrm{C}$ & .317 & 1.000 & $.014^{*}$ & $.031^{*}$ \\
$\mathrm{D}$ & .180 & .375 & $.025^{*}$ & .063 \\
$\mathrm{E}$ & .083 & .250 & .157 & .289 \\
$\mathrm{~F}$ & $.025^{*}$ & .063 & .317 & .625 \\
$\mathrm{G}$ & .157 & .500 & $.008^{*}$ & $.016^{*}$ \\
$\mathrm{H}$ & $.005^{*}$ & $.008^{*}$ & .257 & .453 \\
$\mathrm{I}$ & .317 & .625 & .414 & .687 \\
$\mathrm{~J}$ & $.008^{*}$ & $.016^{*}$ & $.002 *$ & $.002^{*}$ \\
$\mathrm{~K}$ & $.008^{*}$ & $.016^{*}$ & .102 & .219 \\
$\mathrm{~L}$ & .157 & .500 & $.003 *$ & $.004 *$ \\
$\mathrm{M}$ & .317 & 1.000 & .059 & .125 \\
\hline
\end{tabular}

\begin{tabular}{lcccc}
\hline \multirow{2}{*}{ Sample } & \multicolumn{2}{c}{ Lesson Plans } & \multicolumn{2}{c}{ Videotapes } \\
\cline { 2 - 5 } & Wilcoxon & McNemar & Wilcoxon & McNemar \\
\hline $\mathrm{N}$ & $.008^{*}$ & $.016^{*}$ & $.014^{*}$ & $.031^{*}$ \\
$\mathrm{O}$ & $.025^{*}$ & $.063^{*}$ & .414 & .687 \\
$\mathrm{P}$ & $.005^{*}$ & $.008^{*}$ & .317 & 1.000 \\
$\mathrm{Q}$ & $.046^{*}$ & .125 & $.025^{*}$ & .063 \\
$\mathrm{R}$ & $.014^{*}$ & $.031^{*}$ & .059 & .125 \\
$\mathrm{~S}$ & $.317^{*}$ & .625 & .317 & .625 \\
$\mathrm{~T}$ & $.005^{*}$ & $.008^{*}$ & $.003^{*}$ & $.004^{*}$ \\
$\mathrm{U}$ & .180 & .375 & $.046^{*}$ & .125 \\
$\mathrm{~V}$ & $.046^{*}$ & .125 & .083 & .250 \\
$\mathrm{~W}$ & .083 & .250 & .059 & .125 \\
$\mathrm{X}$ & .083 & .250 & $.007^{*}$ & $.012 *$ \\
$\mathrm{Y}$ & .180 & .375 & .317 & .625 \\
$\mathrm{Z}$ & 1.000 & 1.000 & .206 & .344 \\
\hline
\end{tabular}

Note. data marked with * indicates results with a significant difference

movement; 3. Skeletal muscles can be stretched, pulled, and tightened; 4 . It takes only one piece of muscle to complete a movement...

In the design of lesson plans that had a value of 1 , teachers summarized the preconceptions that students usually have through research and teaching experience. Similarly, they designed corresponding parts to help identify the existing preconceptions of students through questionnaires, instead of directly starting a new class while ignoring the existing knowledge of the students. This intuitive performance was more obvious in code 2.4 and investigated whether teachers can use the conceptual change models of teaching that were learned from the WSD-PD in their own teaching designs. This is detailed in the following quotations:

A-Post: This course is based on constructivism and adopts the 5E instructional model. Based on their preconceptions, the course guides students to construct conceptions...Through the construction, the course can expose and eliminate their misconceptions.

T-Post: Using the generative learning instructional model to change students' misconceptions...The four stages [are]: preparation, concentration, challenge and application.

Through the value of one case of code 2.4, it could be clearly observed that the application of the theoretical knowledge that teachers learned in the WSD-PD was very direct. In the cases that had a larger improvement in the post-analysis, teachers were usually able to clarify what kind of teaching model should be applied, what type of class stage divisions should be made, and how preconception exploration and applications of new conceptions should be conducted. However, although the lesson plans could reflect the preliminary planning of teaching, they were also idealized and different from the changeable teaching environment. Therefore, to ascertain whether or to what extent this design can be applied to actual teaching would have required further observation.

\section{Changes in Classroom Practices}

To understand the teachers' classroom teaching, the researchers used FW2 to analyze the classroom teaching videotapes using NVivo software. The approach to coding analysis with FW2 was congruent with FW1. The Kappa value of the two raters' consistency test was 0.804 $(>0.75)$ and Sig. $=0.00(<0.05)$, McNemar test Sig. $=0.824$ $(>0.75)$, indicating that the two raters had effective consistency. The comparison of 936 codes showed that except for one teacher whose total post-analysis score was lower than that of the pre-analysis $(10 \rightarrow 8)$, the postanalysis scores of the remaining samples were improved, with a minimum difference of 1 and maximum difference of 10 . The Wilcoxon results of the groups indicated that the Asymp.Sig. $=0.00 \quad(<0.05)$, which means that there were significant differences between pre- and post-analysis. This result was akin to the analysis of the lesson plans. Namely, the WSD-PD had a positive impact on the overall performance of teachers' teaching practices. A statistical analysis was also conducted on paired samples based on the videotapes submitted by each teacher before and after the PD. The Asymp.Sig. values are listed in Table 3. Twelve teachers in the Wilcoxon analysis showed significant differences, and nine of them also showed significant differences in the McNemar analysis. The number of teachers with individual significant differences decreased slightly, from 10 in lesson plans to 9 in videotapes. This decline indicated that changes in teachers' behaviors in classroom teaching was slightly onerous to changes in lesson plan design. However, it is worth noting that the teachers with significant differences with respect to videotapes did not completely correspond to those with significant differences with respect to lesson plans. 
Table 4. Changes in the frequency of teachers' classroom behaviors

\begin{tabular}{|c|c|c|c|c|}
\hline Category & Item and Description & pre & post & $\%$ \\
\hline Content & Elicitation requests a simple yes/no response $(\mathrm{Y} / \mathrm{N})$ & 18.7 & 12.0 & $-35.8 \%$ \\
\hline \multirow[t]{2}{*}{ Elicitation } & Elicitation requests a relatively short name/state response $(\mathrm{N} / \mathrm{S})$ & 31.4 & 25.9 & $-17.5 \%$ \\
\hline & Elicitation requests description/explanation response (D/E) & 23.3 & 38.2 & $+63.9 \%$ \\
\hline \multirow[t]{2}{*}{ Information } & Teacher provides information to students (TI) & 29.8 & 21.2 & $-28.9 \%$ \\
\hline & Student provides information to other students or teachers (SI) & 1.0 & 5.0 & $+400.0 \%$ \\
\hline \multirow[t]{2}{*}{ Direction } & Teacher intends to cause students to perform some physical or mental activity & 0.8 & 1.0 & $+25.0 \%$ \\
\hline & $\begin{array}{l}\text { Student intends to cause teacher or other students to perform some physical or } \\
\text { mental activity }\end{array}$ & 1.8 & 2.7 & $+50.0 \%$ \\
\hline \multirow[t]{4}{*}{ Uptake } & Teacher makes response to students by evaluative comments & 6.2 & 7.4 & $+19.3 \%$ \\
\hline & Teacher makes response to students by follow-up question & 5.1 & 10.9 & $+113.7 \%$ \\
\hline & Teacher repeats student's answer & 26.7 & 34.3 & $+28.5 \%$ \\
\hline & No response (NU) & 0.8 & 0.0 & $-100.0 \%$ \\
\hline Provide Answer & Teacher provides the answer to their own elicitation & 1.7 & 0.2 & $-88.2 \%$ \\
\hline
\end{tabular}

In contrast to lesson plans, which tended to reflect the framework of classroom design, the analysis of videotapes demonstrated the changes in teachers' increased practical behaviors. Using code 2.3 as an example, the data indicated whether teachers were providing enough time to think after asking a question, especially in situations where students did not respond promptly after being asked. Cases with values of 1 and 0 are as quoted as follows:

U-Post: Who can tell (me) why the raisins in Sprite can go up and down? ... [Silence for four seconds]... Well, I will give you a minute, have a discussion in groups of four and then come back to tell me the answer. [value of 1]

F-Pre: What are those little holes (on the leaves)? ... [Silence for one-and-a-half seconds]... Then I will tell you, those holes are stoma. [value of 0]

In the first case, when the students did not immediately respond to the question, Teacher $U$ allowed enough time for them to find the answer, introduced group discussion (or inquiry activities in other cases of the values of 1), and indicated to students what the time granted was for to help them think deeply. In contrast, in the second case, Teacher F waited for a short period of time after asking questions. Not receiving students' answers in time, she was unwilling to spend more time waiting for the students to think, and directly provided them with the correct answer or the definitions of concepts. Unlike lesson plans that can be carefully revised and improved by teachers before submission, many situations in classroom teaching are sudden. Unexpected events, such as students' failure to answer teachers' questions as expected, may more authentically demonstrate teachers' initial reactions to teaching and students' learning. To further understand the changes in teachers' classroom behaviors, we used part of the coding framework in the TIMSS video study (Stigler et al., 1999), and selected the codes related to content and teacher behavior to analyze the classroom videotapes. The coding comprised five parts, and the frequency and percent of change are shown in Table 4. After analyzing the coding items that specified significant changes, it was understood that the changes in teachers' behaviors in the classroom were mainly reflected in three major aspects: content elicitation mode, information presentation mode, and teachers' responses to students' responses.

Change in content elicitation mode. The overall performance pertaining to content elicitation reflected a decrease in responses where "elicitation requests a simple yes/no response" ( $\mathrm{Y} / \mathrm{N}$, the abbreviations of the codes presented in Table 4 were used in the subsequent analysis) along with an increase in "description/explanation response" (D/E). For the former, the teacher's statement was very simple: let the students judge whether it is right or wrong. Most of these were prepared by teachers before class and could be used quickly. For the latter, teachers' questions were relatively complex. When answering such questions, students were required to describe an object, clarify the reasons, provide solutions, or give reasons as to why something is true or false. Some of these questions were generated immediately by teachers according to the students' learning situations during the teaching process. Teachers could not predict students' answers to such questions, and they needed to think more about how to deal with students' differing answers. Simultaneously, they could also draw more information from the answers after thinking deeply. The following quotations serve as an example:

C-Pre: Carbon dioxide is soluble in water and it can react chemically with water, so we should not choose drainage to collect it, right? $(\mathrm{Y} / \mathrm{N})$

H-Pre: To solve this problem, let us study the pressure of liquids. There is a plastic bag on your desk, what should you do if you want the bag to stick tightly to your hands? (D/E)

Comparison the above examples, it was ascertained that Teacher $C$ integrated the answer into the question 
and presented it to the students. This type of elicitation made the teacher miss the opportunity of obtaining students' ideas. However, in the second example, Teacher $\mathrm{H}$ asked students to propose their own solutions. Consequently, Teacher $\mathrm{H}$ would have the chance to gauge the students' some understanding of the pressure of the liquids. It was deduced that if teachers wanted to know the existing conceptions of students and clarify their thinking, it was impossible to achieve this solely through $\mathrm{Y} / \mathrm{N}$ responses. For the conceptual change strategies in teaching, elicitations that requested $\mathrm{D} / \mathrm{E}$ responses were an effective way to understand students' preconceptions. This change was a reflection of teachers paying more attention to students' thinking.

Change in information presentation mode. In the post-analysis videotapes, the number of teachers who provided information to students decreased, while the proportion of teachers who were encouraging students to present information increased. "Teacher provides information to students" (TI) was simple: teachers directly provided students with the knowledge and the definition of concepts by lecture, while "student provides information to other students or teachers" (SI) was reflected in the teachers' willingness to transfer the opportunities of classroom discourse to students, allowing them to explain the concepts or provide information to other students as depicted in the quotation below:

X-Pre: A mixture formed of small solid particles suspended in a liquid, like soil, is called a suspension. It is formed by small solid particles suspended in a liquid.(TI)

\section{L-Post: Student-6: Our team searched a lot of data and learned that for most plants...a rise in temperature within a certain range can promote photosynthesis, but temperature too high or too low will lead to a decline in photosynthetic intensity.(SI)}

Teacher X's case was a very typical one, in which teachers presented definitions directly to students for memorization. In the second case, Teacher $\mathrm{L}$ asked students to analyze in groups the relationship between the intensity of photosynthesis and temperature. Teacher L did not directly provide a definition but allowed a representative of each student group to explain their groups' conclusion to the whole class, which showed the transfer of discourse opportunity to students. In the classroom, when teachers provided students with the right definition, students' feedback required them to write down and memorize those definitions and rarely think further after they passively received the information. However, when teachers allowed students to present their own information, they conducted a data search, tried to explore the topic, or organize information after deep thinking. This process may assist teachers to better understand what students want to learn, and what their thought processes are.

Change in teachers' responses to students' responses. The most significant change in teacher's responses was that they used more follow-up questions, which implied that students' primary answers could be used as other questions in the subsequent rounds, or new questions could be derived from their answers and transferred to other students. This phenomenon reflected teachers' indepth exploration of students' thinking. They not only desired to know the answers given by students, but also wanted to understand the thought process and reasoning behind the answer, as illustrated in the following quotation:

C-pre: Let's think about that, if I add $\mathrm{NaOH}$ solution to this bottle, what will you see? Student-1: The balloon will bulge. C-pre: Why will the balloon bulge? Student-1: Because the $\mathrm{CO}_{2}$ is absorbed over here, and then...

In this case, Teacher $\mathrm{C}$ not only asked the student to judge the possible phenomenon but also used a followup question to understand how the student came to the conclusion. This response revealed the students' mastery of concepts and the fact that it had a good exploratory effect on understanding the process of students' formation of concepts. Another important function of a follow-up question was that it could result in teachers' avoidance of missing the judgment of misconceptions. When students did not understand concepts clearly, they were not confident and hesitated in answering subsequent questions. In other cases, students simply guessed the answer correctly and did not understand the principles, or arrived at the correct answer through wrong steps. These situations could be effectively explored through follow-up questions.

\section{Evaluation of Different Activities in WSD-PD}

A questionnaire survey was administered after the WSD-PD, and the results are shown in Table 5. It can be determined that the average value of all questions exceeded four, which indicated that teachers had a high degree of appreciation for the overall WSD-PD program. This was especially the case in the evaluation of integrated PD, where the average value of teachers continuing to participate in this form of training reached 4.81. After ranking the survey items from the highest score to the lowert scores across the three activities of the PD program, it was revealed that teachers thought that the greatest role of the workshop was to help them improve their professional ability. In addition to improving professional ability, the seminar helped them to understand the training content that they learned from the workshop. The demonstration class appeared to be the most convenient activity for teachers to 
Table 5. Questionnaire for teachers' feedback on WSD-PD

\begin{tabular}{|c|c|c|c|c|c|}
\hline Activity & Survey item & Min & Max & MED & AVG \\
\hline \multirow[t]{3}{*}{ Workshop } & 1. I can remember the content of workshop & 3 & 5 & 4 & 4.15 \\
\hline & 2. I can understand the content of workshop & 3 & 5 & 4 & 4.27 \\
\hline & $\begin{array}{l}\text { 3. The training content of the workshop is helpful to my professional } \\
\text { development }\end{array}$ & 4 & 5 & 5 & 4.58 \\
\hline \multirow[t]{4}{*}{ Seminar } & 1. I can remember the content of seminar & 3 & 5 & 4 & 4.23 \\
\hline & 2. I can understand the content of seminar & 3 & 5 & 4 & 4.19 \\
\hline & $\begin{array}{l}\text { 3. The training content of the seminar is helpful to my professional } \\
\text { development }\end{array}$ & 4 & 5 & 5 & 4.65 \\
\hline & 4. Seminar helped me understand the training content of the workshop & 4 & 5 & 5 & 4.72 \\
\hline \multirow{4}{*}{$\begin{array}{l}\text { Demonstration } \\
\text { class }\end{array}$} & 1. I can remember the content of demonstration class & 4 & 5 & 5 & 4.61 \\
\hline & 2. I can understand the content of demonstration class & 4 & 5 & 5 & 4.52 \\
\hline & $\begin{array}{l}\text { 3. The training content of the demonstration class is helpful to my professional } \\
\text { development }\end{array}$ & 3 & 5 & 5 & 4.52 \\
\hline & $\begin{array}{l}\text { 4. The demonstration class helped me understand the training content of } \\
\text { workshop }\end{array}$ & 3 & 5 & 4 & 4.39 \\
\hline \multirow[t]{3}{*}{$\begin{array}{l}\text { Integrated } \\
\text { WSD-PD }\end{array}$} & $\begin{array}{l}\text { 1. Through this form of PD, my teaching ability and effectiveness have been } \\
\text { improved }\end{array}$ & 3 & 5 & 4 & 4.31 \\
\hline & 2. I often communicate with program members and other participating teach & 3 & 5 & 4 & 4.31 \\
\hline & $\begin{array}{l}\text { 3. If I had the opportunity, I would like to participate in this form of PD } \\
\text { program again }\end{array}$ & 4 & 5 & 5 & 4.81 \\
\hline
\end{tabular}

remember the training content based on its high overall evaluation.

In the WSD-PD, workshops were determined to be the most important activities for teachers to acquire theoretical knowledge. In these, they acquired considerable information, such as the definition, background, teaching strategies and teaching models of the conceptual change theory through lectures. As the duration of such workshops were concentrated, it was relatively difficult for teachers to cognitively retain the contents. For the seminar, the trainers guided teachers to conduct in-depth discussions on various problems encountered in practice, which may involve acquisition of more difficult forms of knowledge such as students' cognitive development. Therefore, some forms of knowledge may make some teachers feel they are difficult to understand. However, the questionnaire results revealed that teachers perceived that the seminar could help them better understand the knowledge acquired in the workshop and during the teachers' discussions. Similarly, researchers can better understand teachers' learning statuses and explore their learning needs. For example, teacher D asked a question before the first seminar:

\section{Student preconceptions are important, but what can be done to help us explore students' preconceptions?}

Teachers' insights into typical difficulties encountered when working with ideas acquired from PD were rarely found in research, but this issue can improve program implementation at scale (Hill \& Erickson, 2019). In response to this problem, researchers added a part that allowed teachers to discuss the method of acquiring students' preconceptions in the subsequent seminar. In this part, teachers had the opportunity to share their approaches to explore students' preconceptions during their teaching practice, as well as students' preconceptions accumulated through teaching experiences on specific topics. Researchers also added a module for the experts to lead teachers to learn to use the online question bank and search for literature to explore students' preconceptions. Therefore, we believe that the combination of workshops and seminars can help researchers locate the needs of teachers more accurately, help teachers understand training content, and solve problems encountered in the training process. However, the combination of these types of activities is still incapable of satisfying teachers' needs for the application of teaching strategies. Therefore, the entire PD process still needs some activities aimed at improving teachers' classroom teaching to better meet their practical needs.

The demonstration class, which yielded the highest overall evaluation results, was the activity where teachers gained the most in-depth memory of the content. This is an important way for teachers to apply knowledge to practice. Through actual teaching, teachers can better discover the problems encountered in teaching, use the learned knowledge to find solutions to the problems in the form of after-demonstration-class discussions, or bring the inspiration obtained from the discussion into subsequent personal teaching practices. Concurrently, it can also help researchers detect difficulties, even those such as teachers' misconceptions. For example, in the discussion following the first demonstration class, Teacher $\mathrm{Q}$ mentioned: 
This course is about the formation of acid rain. There is no "conception" in it, so it is hard to apply the conceptual change teaching strategy in the course.

During the discussion process, we found that many teachers held this view. They confused the definition of terms that appeared in textbooks along with students' conceptions (in some cases, the two definitions comprised the same word when translated into Chinese). They assumed that only scientific terms with clear definitions were eligible as conceptions and only those conceptions could be taught by conceptual change strategies. White and Gunstone (1989) mentioned that some teachers believe that they only need to tell the students something, and if the students listen, then the concept will change. However, when researchers use the term conceptual change, they are referring to a more fundamental, major shift in belief about principle or in an interpretation of a phenomenon. The authors did not anticipate this situation in the first round of the WSDPD, and this misconception cannot be fully exposed before it is practiced through specific topics meant to be taught. The demonstration class had the most unique practical value as it had the effect of unearthing problems effectively. However, there was not enough time to solve them. Problem solving still required completing the first two types of activities in the WSDPD.

\section{DISCUSSION, CONCLUSION AND IMPLICATIONS}

Professional development is an important means of improving teachers' teaching practice abilities (Luft \& Hewson, 2014; van Driel et al., 2012). Based on the previous discussion on effective $\mathrm{PD}$, duration is an important aspect highlighted in most studies (Desimone, 2009; Garet, 2001; Wilson, 2013). However, the definition of duration is not consistent across studies (Kennedy, 2016). The WSD-PD model was designed and developed on the basis of limited contact hours over an extended time frame. Its purpose is to help more teachers with heavy daily teaching loads to participate in effective PD. The first training attempt as part of the WSD-PD in this study was conducted for junior high school science teachers with "Teaching for Conceptual Change" as the training theme.

The results revealed that the WSD-PD can motivate teachers to generate the willingness to improve their teaching practices. After the WSD-PD, more than $90 \%$ of teachers indicated that they hoped to apply what they had learned in future teaching. Most of them articulated that the training had already positively affected their practice. Through the analysis of lesson plans, the overall sample before and after training showed a significant difference, which indicated that the WSD-PD is effective in influencing their willingness to change their practices.
However, at the individual level, it cannot be ignored that only about half the samples had statistically significant differences, which is different from the teachers' self-assessment. Although teacher selfassessment reports are the main source of data in PD research (van Driel et al., 2012), many researchers consider that self-assessment reports as evaluations cannot completely reveal the actual training effects (Borko et al., 2008; Frechtling et al., 1995; Ingvarson et al., 2005). This study suggests that the "inaccurate" criteria could be inconsistent. From the teachers' perspective, the number of participants who were willing to improve their practice $(\mathrm{N}=24,92.3 \%)$ was consistent with the proportion of actual improvement in coding $(\mathrm{N}=24$, $92.3 \%$ ), even if the increase was slight. However, from the perspective of researchers, the improvement was judged by statistical significance. There was a considerable gap between this statistical analysis and teachers' self-assessment. Therefore, the data from the self-assessment report might not be inaccurate for PD research, but it depends on how researchers define and use it.

From a practical point of view, the WSD-PD can help teachers apply the teaching strategies acquired in PD to practice and make positive changes in their teaching behaviors. Similar to the changes in the lesson plan, videotape coding before and after training exposed a significant difference, in which approximately half of the individual teachers' coding scores in the post-analysis were significantly increased. In the second analysis of the TIMSS video study framework, it was noted that the teachers' teaching presented changes in terms of improved quality of the elicitation, more willingness to allow students to actively provide information, and more use of follow-up questions as uptakes with respect to students. These changes reflect that teachers aspire to pay more attention to students' conceptions, understand their thought processes, and fully expose their misconceptions. The above results prove that the WSDPD is beneficial for the improvement of teachers' instructional practice of implementing conceptual change strategies in teaching in the classroom.

Finally, the evaluation results of different activities confirm our initial idea regarding PD design. Each of the three types of activities in this model have their own places in training. The combination of these three parts has a reasonable logical sequence of theoretical strategy acquisition, practical application, problem identification, and further development of solutions. Especially for teachers who are under great pressure in their daily work and do not have extensive time to participate in centralized training, the WSD-PD can be flexibly embedded into available work gaps and will have important application value in the future.

Our study pays attention to program fidelity in the process of PD design and implementation. However, another result that cannot be ignored is that not all 
teachers can achieve statistically significant improvement through their involvement in the WSDPD. The outcomes of a PD immersion vary across teachers, and the practice effect and direction of each teacher after participating in the same PD will be different. There are several factors that may affect the outcomes of a PD that are not related to implementation fidelity of a particular strategy. Such factors may include previous experience, teaching context, requirements of school leaders, and students' needs. For example, teacher agency may be an important factor leading to different implementation effects of the same PD (Boylan et al., 2018). Highly accomplished teachers have been found to make links to earlier experiences and ideas and show much more flexibility and adaptability than novice teachers (Carpendale et al., 2021). In the design of this study, to ensure the diversity of participants distributed across schools in the city and consider the initiative of teachers, their teaching experience was not considered in the sample selection. Teachers of different teaching ages may have different experiences, and some teachers hold leadership positions in their school, which may also be an important factor affecting the implementation of PD. This suggests that researchers should consider more factors in PD design or develop different PD projects for teachers with different attributes.

Author contributions: All authors have sufficiently contributed to the study, and agreed with the results and conclusions.

Funding: No funding source is reported for this study.

Declaration of interest: No conflict of interest is declared by authors.

\section{REFERENCES}

Aldahmash, A. H., Alshamrani, S. M., Alshaya, F. S., \& Alsarrani, N. A. (2019). Research Trends in İnService Science Teacher Professional Development from 2012 to 2016. International Journal of Instruction, 12(2), 163-178. https://doi.org/10.29333/ iji.2019.12211a

Avalos, B. (2011). Teacher professional development in Teaching and Teacher Education over ten years. Teaching and teacher education, 27(1), 10-20. https:/ / doi.org/10.1016/j.tate.2010.08.007

Blank, R. K., \& de las Alas, N. (2009). The effects of teacher professional development on gains in student achievement: How meta-analysis provides scientific evidence useful to education leaders. Council of Chief State School Officers. https://files.eric.ed.gov/ fulltext/ED544700.pdf

Borko, H., Jacobs, J., Eiteljorg, E., \& Pittman, M. E. (2008). Video as a tool for fostering productive discourse in mathematics professional development. Teaching and Teacher Education, 24, 417-436. https:/ / doi.org/10.1016/j.tate.2006.11.012

Borko, H., Koellner, K. A., Jacobs, J. K., Roberts, S. A., Baldinger, E., \& Risley, R. (2010). Preparing instructional leaders to facilitate mathematics professional development [Paper presentation]. AERA conference 2010, Denver.

Boylan, M., Coldwell, M., Maxwell, B., \& Jordan, J. (2018). Rethinking models of professional learning as tools: a conceptual analysis to inform research and practice. Professional Development in Education, 44(1), 120-139. https://doi.org/10.1080/19415257. 2017.1306789

Bransford, J., Darling-Hammond, L., \& Lepage, P. (2005). Introduction. In L. Darling-Hammond, \& J. Bransford (Eds.), Preparing teachers for a changing world: What teachers should learn and be able to do (pp. 1-39). Jossey-Bass.

Bybee, R. W., Taylor, J. A., Gardner, A., Van Scotter, P., Powell, J. C., Westbrook, A., \& Landes, N. (2006). The BSCS 5E instructional model: Origins and effectiveness. Office of Science Education National Institutes of Health. https://media.bscs.org/ bscsmw/5es/bscs_5e_full_report.pdf

Carpendale, J., Berry, A., Cooper, R., \& Mitchell, I. (2021). Balancing fidelity with agency: understanding the professional development of highly accomplished teachers. Professional Development in Education, 1-19. https:/ / doi.org/10.1080/19415257.2021.1972436

Clarke, D., \& Hollingsworth, H. (2002). Elaborating a model of teacher professional growth. Teaching and Teacher Education, 18(8), 947-967. https:/ / doi.org/10.1016/S0742-051X(02)00053-7

Cordingly, P., Higgins, S., Greany, T., Buckler, N., ColesJordan, D., Crisp, B., Saunders, L., \& Coe, R. (2015). Developing great teaching: Lessons from the international reviews into effective professional development. Teacher Development Trust. https:/ / dro.dur.ac.uk/15834/1/15834.pdf

Dall'Alba, G., \& Sandberg, J. (2006). Unveiling professional development: A critical review of stage models. Review of Educational Research, 76(3), 383-412.

https:/ / doi.org/10.3102/00346543076003383

Darling-Hammond, L., Wei, R. C., Andree, A., Richardson, N., \& Orphanos, S. (2009). Professional learning in the learning profession. National Staff Development Council. https://citeseerx.ist.psu. edu/viewdoc/download?doi=10.1.1.180.6634\&rep $=$ rep $1 \&$ type $=$ pdf

Day, C. (1999). Developing teachers: The challenges of lifelong learning. Falmer Press. https:/ / doi.org/10.4324/9780203021316

Desimone, L. M. (2009). Improving impact studies of teachers' professional development: Toward better conceptualizations and measures. Educational Researcher, 38(3), 181-199. https://doi.org/10.3102 /0013189X08331140 
Fogleman, J., McNeill, K. L., \& Krajcik, J. (2011). Examining the effect of teachers' adaptations of a middle school science inquiry-oriented curriculum unit on student learning. Journal of Research in Science Teaching, 48(2), 149-169. https://doi.org/ 10.1002/tea.20399

Frechtling, J. A., Sharp, L., Carey, N., \& Vaden-Kiernan, N. (1995). Teacher enhancement programs: A perspective on the last four decades. National Science Foundation, Directorate for Education and Human Resources. National Science Foundation. https: / / files.eric.ed.gov/fulltext/ED407246.pdf

Fullan, M. (2008). Curriculum implementation and sustainability. In F. M. Connelly, M. F. He, \& J. Phillon (Eds.), The SAGE handbook of curriculum and instruction (pp. 113-122). Sage. https: / / doi.org/10.4135/9781412976572.n6

Garet, M. S., Porter, A. C., Desimone, L., Birman, B. F., \& Yoon, K. S. (2001). What makes professional development effective? Results from a national sample of teachers. American Educational Research Journal, 38(4), 915-945. https://doi.org/10.3102/ 00028312038004915

Gomez-Zwiep, S. (2008). Elementary teachers' understanding of students' science misconceptions: Implications for practice and teacher education. Journal of Science Teacher Education, 19(5), 437-454. https: / / doi.org/10.1007/s10972-008-9102-y

Granger, E. M., Bevis, T. H., Southerland, S. A., Saka, Y., \& Ke, F. (2019). Examining features of how professional development and enactment of educative curricula influences elementary science teacher learning. Journal of Research in Science Teaching, 56(3), 348-370. https://doi.org/10.1002/ tea. 21480

Grossman, P. (1995). Teachers' knowledge. In L. W. Anderson (Ed.), International encyclopedia of teaching and teacher education (2nd ed., pp. 20-24). Elsevier Science Ltd.

Guskey, T. R. (1999). Apply time with wisdom. Journal of Staff Development, 20, 10-15.

Guskey, T. R. (2003). What makes professional development effective? Phi Delta Kappan, 80, 748750. https:/ / doi.org/10.1177/003172170308401007

Guskey, T. R., Yoon K. S. (2009). What works in professional development. Phi Delta Kappan, 90(7), 495-500.

https:/ / doi.org/10.1177/003172170909000709

Hill, H. C., \& Erickson, A. (2019). Using implementation fidelity to aid in interpreting program impacts: A brief review. Educational Researcher, 48(9), 590-598. https:/ / doi.org/10.3102/0013189X19891436

Ingvarson, L., Meiers, M., \& Beavis, A. (2005). Factors affecting the impact of professional development programs on teachers' knowledge, practice, student outcomes and efficacy. Education Policy Analysis Archives, 13(10), 1-28. https://research. acer.edu.au/cgi/viewcontent.cgi?referer=https: / / xs.hkvisa.net $/$ \&httpsredir $=1$ \&article $=1000$ \&contex $\mathrm{t}=$ professional_dev

Johnson, B., \& Christensen, L. (2004). Educational research: Quantitative, qualitative, and mixed approaches. Allyn \& Bacon.

Kane, T. J., McCaffrey, D. F., Miller, T., \& Staiger, D. O. (2013). Have we identified effective teachers? Validating measures of effective teaching using random assignment. MET Project Research Paper. Bill \& Melinda Gates Foundation.

https:/ / files.eric.ed.gov/ fulltext/ED540959.pdf

Keisler, G. (2017). Leading a learning community. In K. Smith, \& J. Loughran (Eds.), Quality learning: teachers changing their practice (pp. 3-8). Sense Publishers. https://doi.org/10.1007/978-94-6300914-0_14

Kennedy, M. (1998). Form and substance of inservice teacher education (Research Monograph No. 13). National Institute for Science Education, University of Wisconsin-Madison.

Kennedy, M. M. (2016). How does professional development improve teaching? Review of Educational Research, 86(4), 945-980. https://doi.org/10.3102/0034654315626800

Kowalski, S. M., Taylor, J. A., Askinas, K. M., Wang, Q., Zhang, Q., Maddix, W. P., \& Tipton, E. (2020). Examining Factors Contributing to Variation in Effect Size Estimates of Teacher Outcomes from Studies of Science Teacher Professional Development. Journal of Research on Educational Effectiveness, 13(3), 430-458. https://doi.org/ $10.1080 / 19345747.2020 .1726538$

Lerman, S. (1989). Constructivism, mathematics and mathematics education. Educational Studies in Mathematics, 20(2), 211-223. https://doi.org/ 10.1007/BF00579463

Li, N., Zhou, G. X., Huang, X., \& Liu, E. S. (2018). A focus on the current situation and development trend of empirical studies on science education in China: Take the theme of conceptual change as an example. Studies on Science Popularization, 13(6), 512. (in Chinese). https://10.19293/j.cnki.16738357.2018.06.001

Lin, J. W., Yen, M. H., Liang, J. C., Chiu, M. H., \& Guo, C. J. (2016). Examining the factors that influence students' science learning processes and their learning outcomes: 30 years of conceptual change research. Eurasia Journal of Mathematics, Science $\mathcal{E}$ Technology Education, 12(9), 2617-2646. https://10.12973/eurasia.2016.000600a

Loucks-Horsley, S., Stiles, K. E., Mundry, S., Love, N., \& Hewson, P. W. (1998). Designing professional 
development for teachers of science and mathematics. Corwin Press.

Luft, J. A., \& Hewson, P. W. (2014). Research on teacher professional development programs in science. In II S. K. Abell, \& N. G. Lederman (Eds.), Handbook of research on science education. Routledge. https:/ / doi.org/10.4324/9780203097267

McChesney, K. \& Aldridge, J. M. (2019). What gets in the way? A new conceptual model for the trajectory from teacher professional development to impact. Professional Development in Education, 47(5), 834-852. https:/ / doi.org/10.1080/19415257.2019.1667412

Osborne, R., Wittrock, M. (1985). The generative learning model and its implications for science education. Studies in Science Education, 12(1), 59-87. https:/ / doi.org/10.1080/03057268508559923

Posner, G. J., Strike, K. A., Hewson, P. W., \& Gertzog, W. A. (1982). Accommodation of a scientific conception: Toward a theory of conceptual change. Science Education, 66(2), 211-227. http:/ / www.ud.infn.it/URDF/laurea/idifo1/mat eriali/g5/Posner\%20et\%20al.pdf

Pringle, R. M., Mesa, J., \& Hayes, L. (2020). Meeting the demands of science reforms: A comprehensive professional development for practicing middle school teachers. Research in Science Education, 50(2), 709-737. https://doi.org/10.1007/s22265-0189708-9

Santrock, J. W. (2006). Educational psychology classroom update: Preparing for Praxis and practice (2nd ed.). McGraw-Hill Companies.

Smith, J. P., diSessa, A. A., \& Roschelle, J. (1993). Misconceptions reconceived: A constructivist analysis of knowledge in transition. The Journal of the Learning Sciences, 3, 115-163. https://doi.org/10.1207/s15327809j1s0302_1

Stigler, J. W., Gonzales, P., Kwanaka, T., Knoll, S., \& Serrano, A. (1999). The TIMSS videotape classroom study: Methods and findings from an exploratory research project on eighth-grade mathematics instruction in Germany, Japan, and the United States. National Center for Education Statistics. https: / / files.eric.ed.gov/fulltext/ED431621.pdf
Telese, J. A. (2008). Teacher professional development in mathematics and student achievement: A NAEP 2005 [Paper presentation]. Annual meeting of the School Science and Mathematics Association, Raleigh, NC. https:/ / files.eric.ed.gov/fulltext/ED503261.pdf

Treagust, R. D. D. F. (2003). Conceptual change: a powerful framework for improving science teaching and learning. International Journal of Science Education, 25(6), 671-688. https:/ / doi.org/10.1080/09500690305016

van Driel, J. H., Meirink, J. A., van Veen, K., \& Zwart, R. C. (2012). Current trends and missing links in studies on teacher professional development in science education: A review of design features and quality of research. Studies in Science Education, 48(2), 129-160. https://doi.org/10.1080/03057267. 2012.738020

Vosniadou, S. (2003). Exploring the relationships between conceptual change and intentional learning. In G. M. Sinatra, \& P. R. Pintrich (Eds.), Intentional conceptual change (pp. 377-406). Erlbaum.

White, R. T., \& Gunstone, R. F. (1989). Metalearning and conceptual change. International Journal of Science Education, 11(5), 577-586. https://doi.org/10.1080/ 0950069890110509

Wilson, S. M. (2013). Professional development for science teachers. Science, 340(6130), 310-313. https:/ / doi.org/10.1126/science.1230725

Wittrock, M. C. (1974). A generative model of mathematics learning. Research in Mathematics Education, 5, 181-196. https://www.jstor.org/ stable/748845

Yang, Y., Liu, X., \& Gardella, J. A. (2020). Effects of a professional development program on science teacher knowledge and practice, and student understanding of interdisciplinary science concepts. Journal of Research in Science Teaching, 57(7), 1028-1057. https://doi.org/10.1002/tea. 21620

Yin, R. K. (2006). Mixed methods research: Are the methods genuinely integrated or merely parallel? Research in the Schools, 13(1), 41-47. https://www. proquest.com/docview/211166300/fulltextPDF/1 FDC70ADB4514FAFPQ/1 accountid $=8554$

\section{http://www.ejmste.com}

